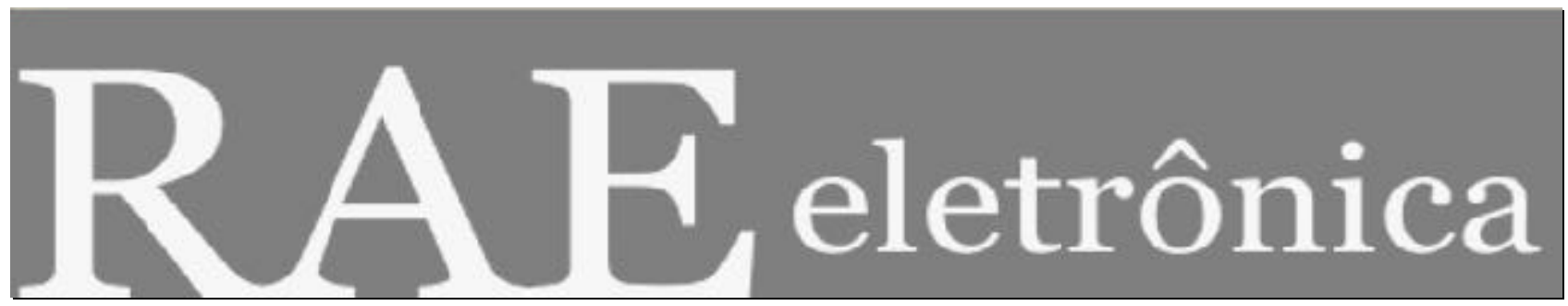

\title{
ADOTANDO A TECNOLOGIA DE INFORMAÇÃO: ANÁLISE DA IMPLEMENTAÇÃO DE SISTEMAS DE “GROUPWARE”
}

Por:

\section{Edna Campos \\ Francisco Lima C. Teixeira}

RAE-eletrônica, v. 3, n. 1, Art. 2, jan./jun. 2004

http://www.rae.com.br/eletronica/index.cfm?FuseAction=Artigo\&ID=1630\&Secao=INFORMAÇÃO \& Volume $=3 \&$ Numero $=1 \&$ Ano $=2004$

CCopyright, 2004, RAE-eletrônica. Todos os direitos, inclusive de tradução, são reservados. É permitido citar parte de artigos sem autorização prévia desde que seja identificada a fonte. A reprodução total de artigos é proibida. Os artigos só devem ser usados para uso pessoal e nãocomercial. Em caso de dúvidas, consulte a redação: redacao@ rae.com.br.

A RAE-eletrônica é a revista on-line da FGV-EAESP, totalmente aberta e criada com o objetivo de agilizar a veiculação de trabalhos inéditos. Lançada em janeiro de 2002, com perfil acadêmico, é dedicada a professores, pesquisadores e estudantes. Para mais informações consulte o site www.rae.com.br/eletronica.

\section{RAE-eletrônica}

ISSN 1676-5648

(C)2004 Editora: Fundação Getulio Vargas - Escola de Administração de Empresas de São Paulo.

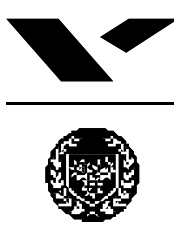

F U N D A G Ä O GETUUO VARGAS

Fycola de Adnirisişradráa de Elipresiss de Sisis Pilullo 


\title{
ADOTANDO A TECNOLOGIA DE INFORMAÇÃO: ANÁLISE DA IMPLEMENTAÇÃO DE SISTEMAS DE “GROUPWARE”
}

\begin{abstract}
RESUMO
O objetivo deste trabalho é o de explorar a relação entre tecnologia e organizações a partir da discussão de como a tecnologia da informação (TI) interage com a estrutura e os agentes humanos. Para tanto, além de explorar teoricamente o tema, visando obter-se um modelo de análise adequado, analisa-se a implantação de sistemas de informação, especificamente de software para o trabalho cooperativo (groupware), em duas organizações. Buscou-se identificar a motivação para a adoção de tais sistemas e a associação existente entre a tecnologia e o ambiente organizacional, no que se refere à estrutura e à ação de agentes. As conclusões apontam a validade do modelo teórico adotado na análise e a necessidade da interação permanente entre os eleme ntos estruturais, os agentes humanos e a tecnologia, quando se objetiva atingir resultados diferenciados.
\end{abstract}

\begin{abstract}
The objective of this work is to explore the relation between technology and organizations arguing how information technology (IT) interacts with the structure and the human agents. In addition to theoretically explore the subject, aiming at getting an adjusted model of analysis, the implementation of software for cooperative work (groupware) in two organizations is analyzed. The aims were to identify the motivation for the adoption of such systems and the existing association between the technology and the organizacional environment, as defined by the structure and the action of agents. The conclusions point to the validity of the theoretical model adopted in the analysis and the importance of permanent interaction between the structural elements, the human agents and the technology, if the objective is to reach differentiated results.
\end{abstract}

\section{PALAVRAS-CHAVE}

Tecnologia de Informação; Groupware (Software); Propriedades Institucionais - Estrutura Organizacional - Agentes Humanos; Grupos de trabalho.

\section{KEY-WORDS}

Information Technology; Groupware (Software); Institutional Properties - Organizational Structure Human Agents; Workgroups. 


\section{INTRODUÇÃO}

As constantes mudanças nas relações econômicas internacionais têm afetado substancialmente a administração das organizações, que buscam meios para garantir sua sobrevivência, melhorar o desempenho e, com isso, promover seu crescimento em mercados cada vez mais competitivos. Ao afetarem o ambiente empresarial, as mudanças preconizadas fazem com que as organizações tradicionais, verticalizadas e burocráticas repensem sua estrutura para se adaptar às novas exigências do mercado. A forma tradicional da organização weberiana vai se tornando, cada vez mais, inadequada, cedendo lugar a novas formas organizacionais (Steil \& Barcia, 1999). Conforme destacam vários autores, dentre eles Tapscott \& Caston (1995), a tendência é as organizações aumentarem sua visão sistêmica, revendo suas operações em busca de uma atuação mais baseada em processos e menos hierarquia.

Nesse contexto, entre os recursos tecnológicos, a Tecnologia da Informação (TI) - complexo tecnológico que envolve computadores, software, redes de comunicação eletrônica públicas e privadas, rede digital de serviços de telecomunicações, protocolos de transmissão de dados e outros serviços (Marcovitch, 1996) - tem sido apontada como importante fator para potencializar o desenvolvimento dos processos produtivos e da gestão das organizações (Pierce \& Robinson, 1989 apud Santos \& Vieira, 1998). A TI cumpre papel significativo, ao ser utilizada como recurso para subsidiar a administração geral das firmas, quando: a) fornece elementos para a definição de estratégias empresariais; b) apóia gestores no acompanhamento dos negócios; c) promove maior rapidez na comunicação interna e com fornecedores e clientes; d) agiliza tarefas burocráticas; e) facilita a execução de atividades administrativas; f) ajuda na gestão da produção.

Várias pesquisas sobre a relação entre tecnologia e organizações têm sido empreendidas desde a década de 1960 (Gerwin, 1981 apud Roberts \& Grabowski, 1996). A partir delas, muitas questões foram levantadas. Tapscott \& Caston (1995) ressaltam que são necessárias mudanças nos processos organizacionais para que a tecnologia implantada surta efeitos positivos em ambientes reestruturados para um novo modo de atuação. Assim, a adoção de tecnologia, em particular dos sistemas de informação, se destaca como elementos integradores e úteis para promover a reestruturação das organizações. Aplicações bem concebidas de TI permitiriam às empresas se tornarem mais planas com a eliminação de camadas gerenciais, onde a TI é um importante elemento na reestruturação não só de processos de negócios, mas de toda a empresa.

Outro fator relevante a se considerar é em que medida a tecnologia influencia e é influenciada pela ação das pessoas. São vários os grupos de interesse - acionistas, empregados de diversos níveis, fornecedores, parceiros de negócio e clientes - atuantes nas organizações. Congregar os desejos desses grupos não é tarefa fácil, ainda mais quando as fronteiras das organizações estão se tornando cada dia mais tênues, não havendo mais separações claras entre os agentes internos (recursos humanos) e os externos (clientes, fornecedores e concorrentes).

O objetivo deste trabalho é o de explorar a relação entre tecnologia e organizações a partir da discussão de como a TI interage com estrutura e agentes humanos. Para tanto, além de explorar teoricamente o tema, com o objetivo de se obter um modelo de análise adequado, analisa-se a implantação de sistemas de informação, especificamente de software para o trabalho cooperativo (groupware), em duas organizações. Acredita-se que uma avaliação criteriosa poderia trazer à luz respostas sobre a melhor forma de se obter resultados com a implantação de TI. 


\section{A análise da relação entre organização e tecnologia}

A mudança organizacional ${ }^{\mathrm{i}}$ é um fenômeno que tem despertado o interesse de diversos estudiosos; e os motivos que levam a essas transformações têm sido associados a várias causas. Embora Brynjolfsson \& Mendelson (1993) relacionem algumas delas - maiores pressões competitivas, mudanças no gosto dos consumidores e disponibilização de novos recursos - eles afirmam que tais mudanças, na atualidade, são, de fato, provocadas, principalmente, pela rápida difusão da TI. Três razões são usadas para embasar essa afirmação. Primeiro, os avanços da TI são, ao mesmo tempo, atuais e exógenos; atuais porque muito dos fundamentos tecnológicos que habilitam a vasta estrutura da informação nos dias de hoje foram desenvolvidos menos que uma geração atrás; e exógenos, pois o desenvolvimento se deu muito mais pelo progresso em áreas de conhecimento externas às organizações, do que pela demanda dos negócios. Segundo, o crescimento nos investimentos de TI é de grande magnitude, gerando o que se denomina de "explosão da informação" (sobrecarga de informações recebidas). Terceiro, a existência de uma tendência básica de que deve haver uma associação entre os custos para gerenciar a informação e a organização da atividade econômica que justifique os custos envolvidos.

Neste trabalho, parte-se da abordagem desenvolvida por Orlikowski (1992) que, ao analisar a relação entre tecnologia e organização, destaca diferentes visões desse relacionamento. Ela propõe um enfoque inovador do tema, partindo da discussão dos primeiros estudos disponíveis até chegar ao seu modelo de análise. Para tal, faz uma caracterização do conceito da tecnologia baseada em dois aspectos: escopo definido como a tecnologia contida, ou hardware, e papel ou função - que corresponde à interação entre tecnologia e organização.

A evolução dos estudos mostra que na associação entre tecnologia e organizações, a princípio a tecnologia era vista como força externa que tinha impacto determinista sobre a estrutura organizacional. Mais tarde, os pesquisadores focaram-se no aspecto humano da tecnologia, vendo esta como o resultado de uma escolha estratégica e da interação social. A pesquisadora sugere uma reconceitualização da relação, considerando que esta se dá com base numa interação daquelas duas visões, sugerindo a noção de dualidade da tecnologia.

Orlikowski (1992) ressalta que, nos modelos tradicionais de análise da tecnologia nas organizações, muitas das ações que resultam na implantação da tecnologia são freqüentemente separadas, no tempo e no espaço, das ações constituídas a partir dela (Figura 1).

Figura 1. Modelos Tradicionais de Desenvolvimento da Tecnologia e Uso da Tecnologia. Fonte: Orlikowski - 1992, p. 407.

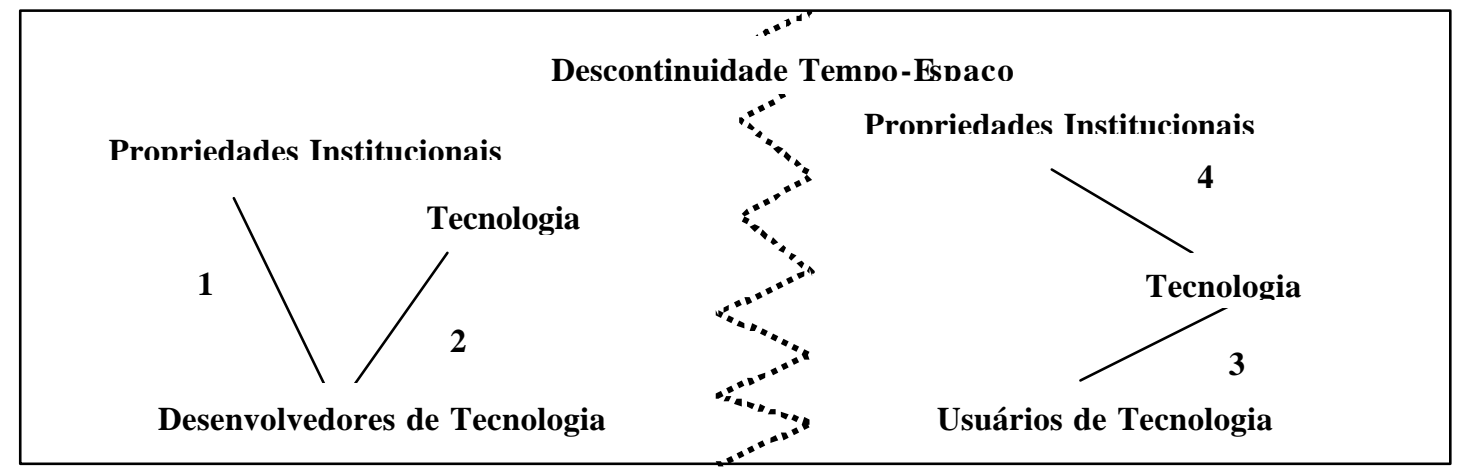




\section{GESTÃO DA INFORMAÇÃO - ADOTANDO A TECNOLOGIA DE INFORMAÇÃO: ANÁLISE DA IMPLEMENTAÇÃO DE SISTEMAS DE "GROUPWARE" \\ Edna Campos - Francisco Lima C. Teixeira}

A Figura mostra o confronto entre o lado do desenvolvimento da tecnologia e a tecnologia propriamente dita, já construída. No lado esquerdo, observa-se que os desenvolvedores de tecnologia, influenciados pelas propriedades institucionais (seta 1), constroem a tecnologia para encontrar os objetivos gerenciais (seta 2). Nesse caso, os estudos consideram a tecnologia como dinâmica e de características contingenciais. Do lado direito da figura, os pesquisadores examinam o uso da tecnologia, focando como os usuários são influenciados por ela (seta 3) e como ela afeta as propriedades institucionais (seta 4 ).

A partir dessa análise dos modelos tradicionais, Orlikowski (1992) introduz seu conceito de dualidade tecnológica que corresponde à noção recursiva da tecnologia: “... a tecnologia é criada e mudada pela ação humana, e é também usada pelos humanos para concluir algumas ações". (pg. 215). Como corolário dessa afirmação, surge a noção de que a tecnologia é "interpretativamente flexível": a interação da tecnologia com organizações é uma função de diferentes atores e contextos sóciohistóricos implicados no seu desenvolvimento e uso. Esta é uma importante constatação, diferente das linhas de estudo até então apresentadas. Tomando-a como referência, depreende-se que o estudo da relação entre tecnologia e organização deve ser dinâmico e abrangente, considerando a interação de diferentes agentes (desenvolvedores e usuários). Para Orlikowski, mais do que posicionar o desenvolvimento e uso da tecnologia como momentos descontínuos, deve-se entender a tecnologia como artefato potencialmente modificável ao longo de sua existência. Assim, chega-se ao Modelo de Estruturação da Tecnologia proposto, que considera os seguintes componentes:

- Tecnologia: artefatos materiais usados na execução de tarefas no local de trabalho;

- Propriedades Institucionais: arranjos estruturais, estratégias de negócios, ideologia, cultura, mecanismos de controle, padrões de procedimentos operacionais, divisão do trabalho, experiência, padrões de comunicação e elementos externos à organização como: competidores, regulação governamental etc.

- Agentes humanos : desenvolvedores, usuários e decisores (decision-makers).

A Figura 2 mostra a relação entre estes componentes. Um detalhamento dessa relação encontra-se na Figura 3. A interação proposta por Orlikowski (1992) baseia-se no processo de mútua ação entre tecnologia e organizações, destacando a influência da tecnologia sobre as organizações e a maneira como os agentes humanos, por sua vez, influenciam e são influenciados pela tecnologia adotada. Este modelo oferece ao estudioso da relação entre tecnologia e organização três pilares a serem analisados: a própria tecnologia adotada, o papel da estrutura-institucional na qual ela se insere e a ação da sociedade envolvida no processo de agregação da tecnologia.

Figura 2. Relação entre componentes da estruturação da Tecnologia. Fonte: Orlikowski - 1992, p.410

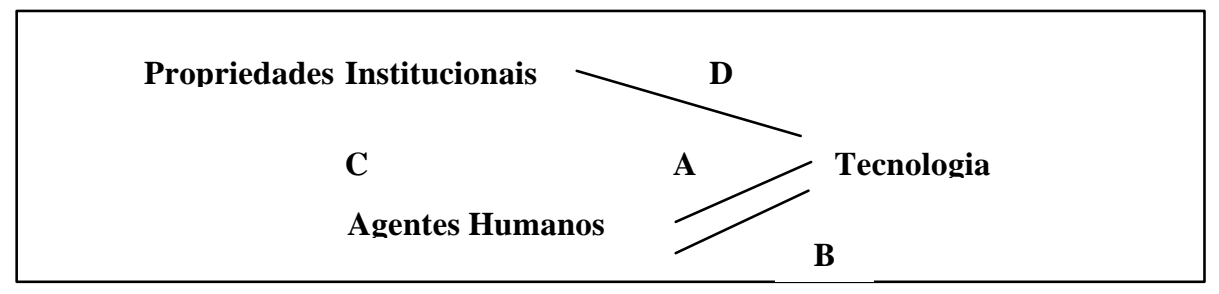


Figura 3. Modelo de Estruturação da Tecnologia. Fonte: Orlikowski -1992, p.410.

\begin{tabular}{|c|l|l|}
\hline Seta & \multicolumn{1}{|c|}{ Tipo de Influência } & \multicolumn{1}{c|}{ Natureza da Influência } \\
\hline A & $\begin{array}{l}\text { Tecnologia como um } \\
\text { produto da ação humana }\end{array}$ & $\begin{array}{l}\text { A tecnologia é modificada pela ação humana, quando estruturando, } \\
\text { desenvolvendo, apropriando e modificando a organização. }\end{array}$ \\
\hline B & $\begin{array}{l}\text { Tecnologia como um meio } \\
\text { da ação humana }\end{array}$ & $\begin{array}{l}\text { Tecnologia facilita e restringe a ação humana através da provisão de } \\
\text { esquemas interpretativos, facilidades e normas. }\end{array}$ \\
\hline C & $\begin{array}{l}\text { Condições institucionais da } \\
\text { interação com a tecnologia }\end{array}$ & $\begin{array}{l}\text { As propriedades institucionais influenciam pessoas em suas interações com a } \\
\text { tecnologia, por exemplo, intenções, normas profissionais, estados da arte em } \\
\text { matérias e conhecimento, padrões de estrutura e recursos disponíveis. }\end{array}$ \\
\hline D & $\begin{array}{l}\text { Consequiências } \\
\text { institucionais da interação } \\
\text { com a tecnologia }\end{array}$ & $\begin{array}{l}\text { A tecnologia influencia as propriedades institucionais de uma organização, } \\
\text { através de reforço ou transformação de estruturas de significação, dominação } \\
\text { e legitimação. }\end{array}$ \\
\hline
\end{tabular}

\section{Delineamento do Escopo da Pesquisa}

Esta seção apresenta o mapeamento dos conceitos considerados para empreender a pesquisa de campo e sua análise, com base nos componentes do Modelo de Estruturação da Tecnologia de Orlikowski (1992).

\section{a) Tecnologia: Sistema de Groupware}

O recurso tecnológico considerado foi sistema de trabalho colaborativo (Groupware), que visa interligar as diferentes áreas dentro da organização, para promover a agilização da comunicação, execução de tarefas e tomada de decisão. Esta categoria de software surgiu no início da década de 90, despontando como elemento para apoiar a evolução das estruturas organizacionais no sentido de ampliar as possibilidades de trabalho em grupos. Conceituar Groupware não é tarefa fácil, uma vez que não há consenso a este respeito. No contexto do estudo apresentado, considerou-se a seguinte definição: "Tecnologia de informação usada para ajudar pessoas a trabalharem juntas de maneira mais eficiente" (Burns apud Al-Omaim, 1997, pg. 30).

As ferramentas de Groupware ou aplicações de trabalho em grupo possibilitam aos indivíduos realizarem tarefas em conjunto, através de uma variedade de aplicações, incluindo correio eletrônico, agendamento em grupo, acesso remoto à rede da empresa, acompanhamento de tarefas, compartilhamento de informações, discussão em grupo, conferência eletrônica, ambiente integrado de colaboração, gerência de fluxo de trabalho (Workflow), acesso Web e gerência de documentos.

Para Groupware (1999) e Candotti \& Hoppen (1999) as ferramentas de Groupware são embasadas em três conceitos (3C's), associados a como as pessoas podem trabalhar em grupo:

Comunicação: suporta a integração fácil e rápida dos grupos, pelo envio de informações, solicitações e instruções. Exemplos de software seguindo esse conceito (Groupware,1999): a) Chat - suporta a comunicação das pes soas, através de mensagens eletrônicas em tempo real, utilizando a Internet; b) Correio Eletrônico (e-mail - electronic mail) - permite a troca de mensagens eletrônicas entre indivíduos ou grupos deles, essa comunicação ocorre de maneira assíncrona ${ }^{\text {ii; }}$ c) Videoconferência para a comunicação por meio da transmissão de imagem e som, via Internet. Colaboração: permite que pessoas trabalhem juntas, em projetos ou processos comuns, possibilitando combinar experiência (conhecimento tácito) e compartilhamento de informações. As tecnologias de colaboração estão sendo influenciadas por duas grandes tendências: tecnologia de redes e globalização. A proliferação das redes 


\section{GESTÃO DA INFORMAÇÃO - ADOTANDO A TECNOLOGIA DE INFORMAÇÃO: ANÁLISE DA IMPLEMENTAÇÃO DE SISTEMAS DE "GROUPWARE" \\ Edna Campos - Francisco Lima C. Teixeira}

e o crescimento da Internet promoveram o surgimento de aplicações conhecidas como Intranet. Coordenação: permite a automação e gerenciamento de seqüência de ações ou tarefas que visam alcançar um objetivo. Para tal, são definidas a ordem em que as tarefas são realizadas e as pessoas envolvidas na sua realização; os processos são disparados por comandos enviados pelos envolvidos ou por ações automáticas previamente programadas (Candotti \& Hoppen, 1999). Como exemplo desta categoria de software tem-se o Workflow, que permite automatizar e coordenar os processos de negócios de uma empresa, aplicando-se a processos que exigem a preparação de informações estruturadas e ordenadas. Ele serve para determinar o fluxo do processo, mostrando as etapas corretas para a sua concretização, permitindo o acompanhamento de todas as atividades que o constituem (Carvalho \& Ferreira, 2000). A Figura 4 mostra como os 03 conceitos se completam, subsidiando o conceito de groupware.

Figura 4. Integração dinâmica da comunicação, colaboração e coordenação. Fonte: Adaptado de Groupware (1999).

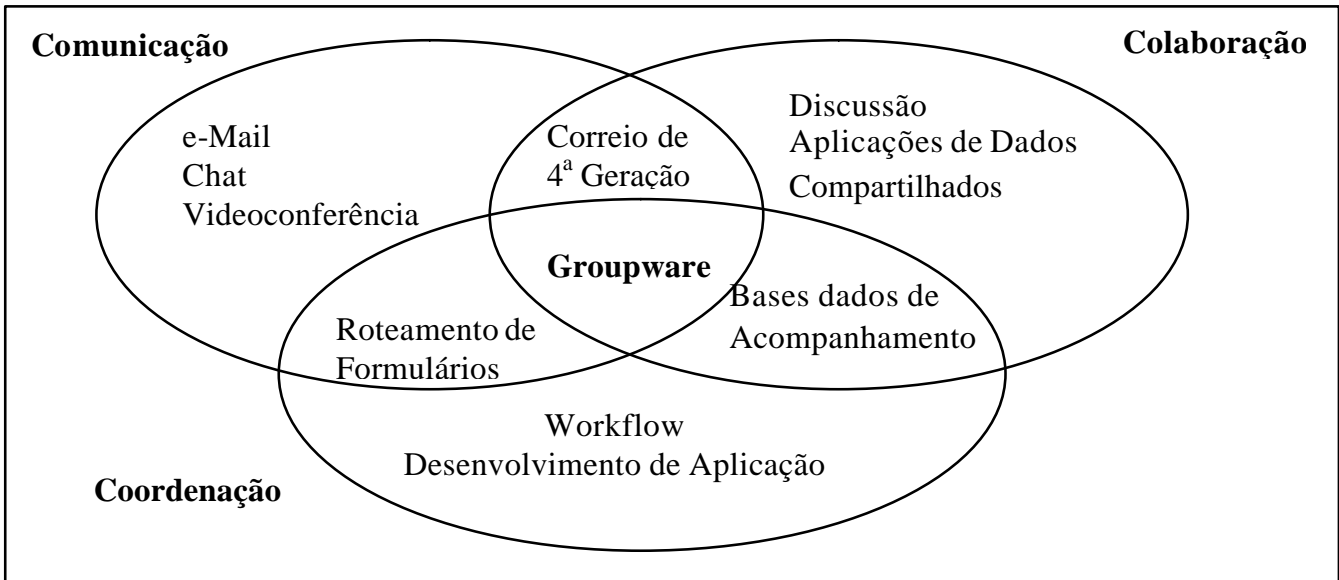

De acordo com AlOmaim (1997), para que um sistema de Groupware seja considerado eficiente, ele deve congregar três componentes: interface amigável para o usuário, ambiente de desenvolvimento para programar aplicações que atendam às necessidades específicas da empresa e infra-estrutura arcabouço do sistema que suporte os outros dois componentes.

\section{b) Propriedades-Institucionais: estrutura organizacional}

O conceito de estrutura organizacional adotado neste artigo é o de Vasconcelos e Hemsley (1997), que consideram a estrutura organizacional como:

"O resultado de um processo através do qual a autoridade é distribuída, as atividades desde os níveis mais baixos até a alta administração são especificadas e um sistema de comunicação é delineado permitindo que as pessoas realizem as atividades e exerçam a autoridade que lhes compete para o atingimento dos objetivos organizacionais" (pg. 10).

Esse conceito pode ser completado por Mintzberg (1995),.que associa a estrutura organizacional às maneiras como o trabalho pode ser dividido em tarefas distintas e como elas são coordenadas. Motta (1999) destaca que, no sentido clássico, a estrutura era usada visando diminuir ou até eliminar as 
incertezas, através de uma maior rigidez da autoridade e poder. Privilegiavam-se as dimensões internas da organização, praticamente desconsiderando as transações com o ambiente externo a ela. Nesse contexto, a organização era tratada como um sistema fechado. Porém, a velocidade e intensidade das transformações sociais, econômicas e tecnológicas fizeram com que as organizações se tornassem mais vulneráveis e integradas às mudanças do ambiente externo. Estruturas rígidas não são mais suficientes para eliminar incertezas, e as ligações com o exterior estão afetando os comportamentos administrativos. Muitos consideram que não mais existe uma forma única de desenhar a estrutura e sim estruturas contingenciais (Zanela et alli, 1999), ou seja, diferentes estruturas que resultam de fatores contingenciais internos e externos, associados a cada organização.

Neste estudo, foram considerados fatores estruturais discutidos nos trabalhos de Mintzberg (1980, 1981 e 1995), visto que eles sintetizam vários pontos de análise, detalhando aspectos estruturais e situacionais, agrupados de forma lógica e em consonância com a abordagem contingencial aqui adotada. Mintzberg (1995) considera que as organizações são estruturadas para apreender e direcionar sistemas de fluxos e determinar inter-relacionamentos em suas diferentes partes básicas:

Núcleo operacional: empregados relacionados à produção do negócio central da organização, fabricando produtos ou prestando serviços;

Cúpula estratégica: formada pelo principal administrador e outros executivos de alto nível; responsáveis pelo cumprimento eficaz da missão da organização;

Linha intermediária: com gerentes de médio escalão, que ligam as duas primeiras partes;

Tecnoestrutura : formada por analistas fora do fluxo de trabalho operacional; podem planejar e alterar ou treinar os indivíduos que executam as tarefas, sem as executarem por si;

Assessoria de apoio: formada pelos grupos de suporte indireto à organização (restaurante da empresa, departamento de segurança, assessoria jurídica etc.).

A partir das partes básicas da organização e da combinação de três fatores variáveis - mecanismos de coordenação, parâmetros essenciais e fatores situacionais - as organizações apresentam configurações próprias (Mintzberg, 1995):

- Os Mecanismos de coordenação: ajustamento mútuo (coordenação do trabalho feita pelos trabalhadores), supervisão direta (coordenação feita pela pessoa responsável através de ordens diretas), padronização do processo de trabalho (trabalho coordenado por regulamentos e regras), padronização de resultados (os padrões exigidos estão relacionados ao produto final do processo - por exemplo, às dimensões do produto ou ao desempenho), padronização de habilidades e conhecimentos (coordenação através da internalização de habilidades e conhecimentos). À proporção que o trabalho organizacional se torna mais complexo, os meios que facilitam a coordenação parecem mudar.

- Parâmetros Essenciais : especialização da tarefa, forma de agrupamento e dimensões das unidades, instrumentos de interligação, descentralização da tomada de decisão

- Elementos Situacionais: são fatores contingenciais que afetam o desenho da organização (Mintzberg, 1995). Dentre eles, este estudo considerou os aspectos característicos da estrutura que influenciam diretamente a ação dos agentes humanos: idade e dimensão das organizações, 


\section{GESTÃO DA INFORMAÇÃO - ADOTANDO A TECNOLOGIA DE INFORMAÇÃO: ANÁLISE DA IMPLEMENTAÇÃO \\ DE SISTEMAS DE "GROUPWARE" \\ Edna Campos - Francisco Lima C. Teixeira \\ estabilidade, complexidade e influência do poder.}

Mintzberg (1995) conclui que as configurações não existem em absoluto, sendo figuras para representar a realidade das organizações que são extremamente complexas. As estruturas reais podem ser híbridas ou refletir as características de uma organização num determinado momento, podendo existir outras configurações não retratadas.

\section{c) Agentes Humanos}

Conformidade, comprometimento, lealdade e internalização das normas organizacionais são aspectos estimulados pela socialização. Esse processo se inicia com o desenvolvimento da declaração de visão e missão organizacionais, onde as metas e valores centrais dos dirigentes são articulados para guiar as estratégias organizacionais e ações diárias dos empregados. É o investimento na habilidade de tratar comportamentos que irá ditar o ritmo da força de trabalho. As práticas organizacionais voltadas à socialização tornamse peças fundamentais neste processo de habilitação comportamental (Steil \& Barcia, 1999).

A análise dos agentes humanos envolvidos no processo de adoção de tecnologia passa por considerar aspectos como os valores por eles adotados, sua conseqüente influência sobre o comportamento nas organizações, ditando o ritmo da cultura organizacional.

Para o desenvolvimento da pesquisa definiu-se por avaliar 03 elementos básicos associados aos agentes humanos - cultura organizacional, motivação e resistência à mudança.

Cultura organizacional: Weber já havia sugerido que uma análise organizacional adequada configurase sempre em uma análise da cultura organizacional (Weber apud Clegg, 1994). Em termos operacionais, a cultura possibilita uma mudança na natureza do controle organizacional. Ela é tratada por Schein (1984, apud Zanela \& Soares, 1999) como um modelo de pressupostos que os grupos inventam, descobrem ou desenvolvem para lidar com problemas de adaptação; assim que estes pressupostos são tidos como válidos, são repassados a outros membros da organização, tornando-se a referência para se lidar com aqueles tipos de problemas. Assim, a cultura ajuda a normatizar o comportamento dos atores organizacionais, pois sanciona o comportamento, estabelecendo as bases a partir das quais as pessoas são recompensadas ou punidas, confrontadas ou encorajadas, ou, ainda, postas em ostracismo quando violam estas normas (Simons, 1995, apud Steil \& Barcia, 1999).

Child \& Loveridge (1990) consideram que a introdução e aplicação de novas tecnologias nas organizações são um processo no qual vários grupos - influenciados pelas propriedades institucionais da organização - potencialmente participam e buscam influenciar decisões e resultados. Por causa disso, acreditam que um maior envolvimento das partes interessadas na preparação de especificações para a seleção de sistemas tecnológicos nos estágios mais iniciais do processo deve levar a uma maior chance de promover soluções inovativas, utilizando as possibilidades tecnológicas.

Buscou-se identificar se as organizações analisadas tinham propensão para o trabalho em equipe, e se já fazia parte da sua cultura organizacional essa tendência, ou ainda, se houve mudanças na forma de trabalho para se adotar o groupware.

Motivação: a pesquisa procurou saber: a) em que medida as pessoas se sentiram mais ou menos motivadas a usar o novo sistema; b) se elas perceberam ganhos com a utilização através da conseqüente automatização de tarefas operacionais; c) se houve incremento na visão sistêmica das operações da 
organização; d) e se houve agilização na comunicação e recebimento de informações, permitindo aumento de autonomia na solução de problemas e to mada de decisão.

A motivação relaciona-se ao modo como as pessoas se dispõem a agir em favor do uso do sistema, de maneira a buscar resultados efetivos com isto. Foram consideradas as variáveis:

- utilidade percebida: grau em que uma pessoa acredita ter seu trabalho melhorado a partir do uso de um sistema (Davis, 1986 apud Dias, 2000). Capturada através da percepção dos agentes humanos em relação a aspectos como: qualidade do trabalho, rapidez na execução de tarefas, melhoria de produtividade, utilidade dos computadores para o trabalho;

- facilidade percebida: como se acredita usar um sistema sem grande esforço (Davis, 1986 apud Dias, 2000). Essa variável foi analisada com base no entendimento da percepção dos indivíduos em relação a: facilidade do uso da tecnologia em si, facilidade do uso do sistema para agilizar a execução de tarefas, facilidade do uso do sistema para apoio na comunicação e tomada de decisões;

- prazer percebido: associado a se a atividade de se usar o computador é prazerosa, independente de se obter qualquer conseqüência de desempenho (Davis et alli, 1992 apud Dias, 2000). Para capturar essa percepção foi questionado diretamente aos usuários se eles sentiam prazer em usar o sistema.

Na pesquisa foi questionado se as pessoas se sentiram motivadas a utilizar o sistema de groupware e se perceberam essa inclinação em seus colegas de trabalho.

Resistência à Mudança: não se pode deixar de falar sobre a resistência à mudança e tentativa de manutenção de um status quo que muitas pessoas criam, impedindo o sucesso de empreitadas em torno do uso de novas tecnologias. Para identificar se houve resistência à implantação do sistema de groupware, buscoutse entender se a organização tem uma cultura voltada para mudanças e se os indivíduos de maneira geral se sentem confortáveis com esses processos.

\section{Procedimentos Metodológicos da Pesquisa Empírica}

No trabalho, buscou-se explorar: a) como a tecnologia adotada estava associada à estrutura das organizações, contribuindo para modificá-las, se necessário; b) como os diferentes agentes humanos atuaram na implantação e no uso de tais sistemas.

Para o desenvolvimento deste estudo, torna-se necessário que se discorra sobre os três principais grupos de pessoas envolvidas nos processos de adoção de tecnologias. O grupo da alta gerência das organizações, que busca utilizar a TI como ferramenta estratégica; os usuários, que têm objetivos bem específicos (operacionais) a serem atendidos com a implantação dos sistemas e, por isto, deveriam ser envolvidos no processo desde a fase inicial de levantamento; e o terceiro grupo, o dos especialistas em TI que, conhecendo os recursos técnicos, nem sempre entendem claramente quais os objetivos que a alta gerência e usuários pretendem atingir, como também nem sempre sabem disponibilizar os recursos de TI de maneira a atingir esses objetivos. Tendo interesses e pontos de vista diferentes, em muitos casos, têm-se um hiato entre as expectativas desses grupos. Além do fato de que suas ações se dão de maneira distinta, impactando de forma diversas nos resultados da adoção da tecnologia. Na pesquisa, foram utilizados questionários e entrevistas diferentes para cada um dos três grupos. 


\section{Descrição dos Procedimentos}

Edna Campos - Francisco Lima C. Teixeira

A coleta de dados teve como foco inicial os seguintes pontos:

- como as estruturas das organizações influenciaram ou foram influenciadas pela tecnologia;

- como se deu a interação dos agentes humanos no processo de implantação e no uso dos sistemas;

- se houve algum tipo de avaliação dos resultados obtidos (ex.: diminuição de custos, ganho de produtividade etc.) a partir da adoção de tais sistemas.

A partir desses pontos, foram classificados três grupos de informação: Grupo 1 (Caracterização da organização); Grupo 2 (Avaliação dos componentes de Orlikowski: Tecnologia, Estrutura Organizacional e Agentes Humanos) e Grupo 3 (Resultados produzidos).

A pesquisa começou a partir de entrevistas com diretores, gerentes de TI das organizações, a fim de se identificar o comprometimento da alta administração com a adoção do sistema, bem como encontrar elementos que apontassem para os resultados advindos da sua implantação. Em seguida, foram entrevistadas pessoas de diferentes níveis hierárquicos, considerados como usuários "chaves", contratantes dos aplicativos de groupware implantados, visando identificar as mudanças estruturais e comportamento dos indivíduos, associados à adoção do sistema. Foram ainda coletadas as impressões de usuários comuns, através de um questionário padrão. A coleta de dados foi baseada também em documentos e observações gerais da estrutura, processos de trabalho e atitude dos indivíduos.

\section{Etapas de Avaliação}

Visando uma sistematização de mais fácil entendimento, as questões foram associadas a etapas temporais (o antes, o durante e o depois) relacionadas à implantação de sistemas de informação de maneira geral. Dessa forma, a proposta foi associar os três grupos de informação a estas três etapas:

O planejamento e acompanhamento técnico do processo de implantação em si não foram aqui considerados por estarem associados a questões técnicas e operacionais, distanciando-se, portanto, dos objetivos deste trabalho.

Etapa 1 - Decisão da adoção do sistema: identificação dos fatores considerados para justificar a implantação dos sistemas. Se foram analisados aspectos puramente técnicos; meramente modistas sistema em uso por outras organizações - ou se as organizações levaram em conta a real necessidade do uso de tais sistemas, visando dar subsídios ao cumprimento dos objetivos de negócio, podendo ser estes genéricos ou específicos a uma determinada área ou departamento. Procurourse identificar também que tipo de planejamento foi elaborado para a implantação do sistema. Levantourse ainda o histórico da implantação.

Etapa 2 - Implantação e uso do sistema: foram analisados os componentes organizacionais, estrutura organizacional e ação dos agentes humanos (comportamento), buscando-se identificar em que medida eles influenciaram e foram influenciados pela adoção do sistema.

Etapa 3 - Avaliação final do processo de implantação - verificação dos resultados: avaliação dos resultados da implantação do sistema de groupware sobre as organizações. Buscou-se classificar os resultados como benefícios quantificáveis e não quantificáveis, afetando parâmetros de negócios 
(receita, custo, produtividade, etc).

\section{Instrumentos de Pesquisa}

Para a coleta de informações referentes a cada um dos três grupos, foi utilizado um ou mais instrumentos (documentos, entrevistas e questionários), e entrevistadas pessoas com diferentes perfis e cargos na organização.

Grupo 1 - Caracterização da Organização: a caracterização não tinha objetivos diretamente relacionados aos resultados da pesquisa, visa apenas apresentar as organizações no que tange a seu histórico e sua missão,

Grupo 2 - Avaliação dos componentes de Orlikowski: tecnologia, estrutura organizacional e agentes humanos: o grupo visava apresentar a tecnologia adotada (Sistemas de Groupware), relacionando os recursos implantados, bem como o histórico da implantação. Em seguida, foram detalhadas as características estruturais das organizações e a ação dos agentes humanos envolvidos no processo de implantação e uso do sistema.

Grupo 3 - Resultados produzidos: avaliação efetuada junto a profissionais técnicos (especialistas de informática) envolvidos nos projetos de implantação das aplicações e ainda com gerentes, coordenadores ou usuários chaves, responsáveis pela contratação dos aplicativos de groupware, visando identificar os resultados obtidos com a implantação do sistema e aplicativos.

A Figura 5 mostra a relação de cada grupo de informação com as etapas de avaliação e instrumentos utilizados.

Figura 5. Instrumentos de Pesquisa Utilizados. Fonte: Elaboração própria

\begin{tabular}{|l|c|c|c}
\cline { 2 - 4 } \multicolumn{1}{c|}{} & \multicolumn{3}{c}{ Etapa de Avaliação } \\
\hline $\begin{array}{l}\text { Grupo de Informação } \\
\text { Organização }\end{array}$ & $\begin{array}{c}\text { 1 - Decisão da } \\
\text { adoção do sistema }\end{array}$ & $\begin{array}{c}\text { 2- Implantação e } \\
\text { uso dos sistemas }\end{array}$ & $\begin{array}{c}\text { 3- Avaliação final do } \\
\text { processo de implantação }\end{array}$ \\
\hline $\begin{array}{l}\text { 2- Avaliação dos componentes } \\
\text { de Orlikowski (Tecnologia, } \\
\text { Estrutura e Agentes Humanos) }\end{array}$ & $\begin{array}{c}\text { Roteiro de } \\
\text { levantamento das } \\
\text { características }\end{array}$ & $\begin{array}{c}\text { Roteiro de } \\
\text { levantamento das } \\
\text { características }\end{array}$ & $\begin{array}{c}\text { Roteiro de levantamento } \\
\text { das características }\end{array}$ \\
\hline 3- Resultados Obtidos & $\begin{array}{c}\text { Entrevistas e } \\
\text { Questionários }\end{array}$ & \\
\hline
\end{tabular}

\section{Resultados do Trabalho Empírico}

Esta seção apresenta os resultados da coleta de informações de acordo com os grupos de informações detalhado na Figura 5.

\section{Grupo 1 - Caracterização das Organizações}

A pesquisa foi realizada em duas organizações de portes e segmentos diferentes:

- Organização ALFA: empresa do segmento de petroquímica, localizada no Pólo Petroquímico de Camaçari/BA. 


\section{GESTÃO DA INFORMAÇÃO - ADOTANDO A TECNOLOGIA DE INFORMAÇÃO: ANÁLISE DA IMPLEMENTAÇÃO \\ DE SISTEMAS DE "GROUPWARE" \\ Edna Campos - Francisco Lima C. Teixeira}

- Organização BETA: instituição voltada para a intermediação da oferta e demanda tecnológica entre agentes econômicos, sociais e institucionais, localizada em Salvador/BA.

Os critérios para a escolha foram distintos. A Organização ALFA foi escolhida por ser uma empresa de grande porte, ou seja, com faturamento anual em torno de R \$ 390 milhões; com aproximadamente 300 empregados e terceiros; com tradição na utilização de sistemas de groupware (o uso de sistemas com essa filosofia se iniciou há mais de cinco anos); com várias unidades utilizando aplicações específicas desenvolvidas nesse ambiente; facilidade de acesso a documentos e pessoas, o que possibilitou a coleta de informações da pesquisa. A escolha da Organização BETA foi motivada pelo fato de ter sido estruturada, desde sua fundação (1998), para desenvolver suas atividades baseada em sistema de trabalho colaborativo (groupware), possibilitando-lhe exercer sua finalidade que é a prestação de serviços de informação relacionada à oferta e demanda tecnológica. Na pesquisa, BETA foi utilizada como grupo de controle, para servir de contraponto para a análise da pesquisa empreendida em ALFA.

As fontes de dados utilizadas foram: observação, análise de documentos, entrevistas semi-estruturadas e questionários diferenciados, respondidos por pessoas ocupando cargos distintos nas organizações diretores, gerentes diversos e usuários. A pesquisa foi realizada entre os meses de março a agosto de 2001.

\section{Grupo 2: Avaliação dos componentes do modelo de Olikowski (1992):}

Os componentes tecnologia, propriedades institucionais e agentes humanos foram observados à luz dos resultados da pesquisa de campo empreendida nas organizações analisadas.

\section{a) Tecnologia: Sistema de Groupware}

Sobre a tecnologia em foco, verificou-se que ela dispõe de subsídios para promover a interação entre as pessoas no desempenhar de suas atividades na organização. Em ambas as organizações estudadas, essas características têm sido utilizadas em profusão, ao contrário de muitas outras organizações públicas e privadas que adotaram esse tipo de sistema, mas utilizam apenas parte de seu potencial - como exemplo, o uso exclusivo do correio eletrônico, privando-se da utilização de inúmeras aplicações que poderiam ser adotadas para auxiliar nos processos diversos da vida organizacional cotidiana.

A Organização ALFA utiliza diversas aplicações, desenvolvidas no ambiente de groupware, que promovem a integração de departamentos e até de toda a empresa, otimizando processos que, antes da adoção de sistema automatizado, eram demorados e não inspiravam confiança nas pessoas que deles dependiam. Além disso, outras aplicações estão em planejamento ou desenvolvimento e serão implantadas para informatizar processos, valendo ressaltar que as entrevistas e questionários apontaram uma grande euforia no sentido de desenvolver cada vez mais aplicações no ambiente de groupware. Muitas delas, no entanto, precisam ser rigorosamente avaliadas para definir se, de fato, constituem a melhor ferramenta para todos os casos.

No caso da Organização BETA, a utilização da tecnologia é intensa, a ponto da estrutura e processos operacionais terem sido configurados, em sua concepção, a partir da filosofia de trabalho colaborativo, baseado no uso de sistema de groupware. 
Usando a classificação de Mintzberg (1980, 1981 e 1995) caracteriza-se a estrutura de ALFA como segue. O Mecanismo de Coordenação predominante é a padronização por processo de trabalho, com regras e regulamentos para orientar a sua execução, associada a uma supervisão direta que orienta o cumprimento das tarefas. Quanto aos Parâmetros Essenciais à Organização, a pesquisa indica que a empresa possui especialização de tarefas com divisão básica do trabalho, existindo delineamento da superestrutura como base no agrupamento das unidades, com supervisão direta em cada uma delas. O delineamento das ligações laterais é calcado em intensa comunicação informal, principalmente entre os coordenadores de área, promovendo discussões constantes entre os pares para a tomada de decisões que ocorrem geralmente em equipes multidisciplinares. Assim, a tomada de decisão é baseada na descentralização horizontal. A discussão dos Elementos Situacionais aponta uma empresa de 24 anos, com comportamento informal, onde se pratica relacionamento aberto nas discussões. Quanto à influência do mercado, a organização se mostrou, através da pesquisa de campo, como sendo relativamente estável, visto que, sendo líder no segmento que atua, não sofre das intempéries provocadas pela ação da concorrência. Por outro lado, ALFA mostrou ser simples, possuindo uma configuração estruturada em partes facilmente compreensíveis, com áreas bem definidas, geridas por coordenadores que se reportam diretamente aos executivos principais. Identificou-se baixa influência do poder externo sobre a organização, que não é afetada de maneira significativa pelas pressões do mercado para orientar seus negócios ou decisões, pois sendo ALFA detentora de alto Market Share, possui autonomia para direcionar suas políticas e estratégias de atuação. Ainda em consonância com a classificação de Mintzberg (1980, 1981 e 1995), a caracterização retratada orienta para o fato de que a empresa pode ser entendida como uma Burocracia Mecanizada. Entretanto, conforme o próprio Mintzberg (1995) destaca, estas configurações não são formas absolutas e representam a organização num dado momento, no caso em questão, na época da pesquisa de campo.

Quanto a BETA, a pesquisa de campo revelou que na organização existe um misto de dois Mecanismos de Coordenação: 1) ajustamento mútuo, havendo casos em que os próprios trabalhadores coordenam as atividades a serem desempenhadas, por comunicação e 2) padronização de habilidades e conhecimentos, neste mecanismo a coordenação se baseia na internalização de habilidades e conhecimentos de seus colaboradores para executar o trabalho. BETA utiliza-se da tecnologia - groupware - para identificar recursos técnicos e humanos para a produção dos resultados do trabalho solicitado. É a prática da gestão do conhecimento através do uso da tecnologia de informação. A caracterização dos Parâmetros Essenciais à Organização indica que, no delineamento das ligações laterais, predomina um sistema de comunicação informal, havendo ajustamento mútuo na execução do trabalho, com conjuntos de atividades a serem desempenhadas e processos decisórios ad hoc. Nesta organização, o delineamento do sistema de tomada de decisão é baseado na descentralização horizontal. Sobre os Elementos Situacionais, a instituição é uma organização jovem, com 3 anos e meio de existência, e comportamento informal, onde se pratica gerenciamento participativo e franca discussão para a tomada de decisões. Em relação ao meio ambiente, a organização mostrou ser influenciada pelas demandas do mercado, visto que é justamente este o seu papel, prestar serviços à comunidade - pequenas e médias empresas - no sentido de provê-la de informações necessárias à viabilização de projetos. A organização mostrou ser simples, possuindo uma configuração estruturada em áreas facilmente compreensíveis, geridas por três coordenadores que se reportam diretamente ao executivo principal. Os profissionais ligados a essas áreas atuam numa estrutura matricial, atendendo demandas geradas em todas as três coordenações. Por esssas características, a classificação de Mintzberg que mais representava BETA, no período em que foi desenvolvida a pesquisa de campo, foi a de uma Burocracia Profissional. 


\section{c) Ação dos Agentes Humanos}

Edna Campos - Francisco Lima C. Teixeira

A análise dos agentes humanos se apoiou em três elementos básicos: cultura organizacional, motivação e resistência à mudança

Em ALFA a observação desses elementos indica uma organização onde se pratica o trabalho em grupo, com intensa comunicação entre as áreas. As mudanças são uma constante na empresa, o que gerou, nos últimos anos, a diminuição dos níveis hierárquicos para agilizar os processos e tomada de decisões. Dessa forma, novas práticas de trabalho ou adoções de recursos diversos, sejam eles tecnológicos ou de outra natureza, são, de maneira geral, bem aceitas sem resistência que comprometa a nova situação sendo implementada.

A adoção da tecnologia de groupware foi provocada pela necessidade de informatizarem áreas cujos processos e rotinas eram administrados manualmente; em função disso, a motivação geral para o uso do sistema e das aplicações implantadas foi, e ainda é, grande. Excetuando-se uma aplicação analisada, as demais aplicações são vastamente utilizadas e têm seus benefícios e resultados reconhecidos pelos usuários.

Sendo BETA uma instituição de apoio ao avanço tecnológico das pequenas e médias empresas, observou-se uma cultura voltada para a valorização das inovações e para a disseminação do conhecimento entre os profissionais que nela atuam - através do trabalho em equipe - e para os clientes que requisitam serviços da organização. Com isso, é grande a motivação para o uso de recursos que venham a contribuir para o acesso rápido a informações que possam viabilizar os projetos imaginados pelos clientes.

Dentre as coordenações existentes em BETA, não há resistência por parte da coordenação geral e de duas coordenações de área para o uso do sistema de groupware, pelo contrário, o depoimento comum aos entrevistados é o de que o uso de tal sistema é primordial para o desempenho das atividades. Mas existe foco de resistência ao uso de sistema colaborativo em uma das coordenações. O seu coordenador declarou não haver interesse de sua área na utilização dos recursos providos pelo ambiente de groupware, uma vez que o desenvolvimento de aplicações nesse ambiente é caro. Assim, as atividades executadas por essa coordenação se apóiam parcialmente no uso de sistema colaborativo - utilizam o correio eletrônico e agenda.

\section{Grupo 3: Resultados Obtidos}

Como destacado nos objetivos deste trabalho, procuroutse avaliar os resultados da adoção da tecnologia do ponto de vista da organizações pesquisadas. Acredita-se que essa avaliação é importante, embora não faça parte do modelo analítico utilizado.

Nas duas organizações não houve mensuração quantitativa acerca dos resultados obtidos com a implantação do sistema de groupware. Nos dois casos, há a percepção de que houve ganhos em agilidade na disseminação das informações - é a democratização da informação - podendo ser acessada por todos.

No caso de ALFA, a maioria dos entrevistados fez questão de retratar os ganhos obtidos com a rapidez nos processos que foram automatizados, bem como maior credibilidade que lhes foi conferida. Porém, houve quase unanimidade quando destacaram não terem sido criados mecanismos que mensurassem os ganhos obtidos com a implantação do ambiente de groupware - correio eletrônico e agenda eletrônica 
e aplicações adotadas.

Para BETA, a avaliação foi mais simples, visto que suas operações principais foram estruturadas para ocorrerem com base no ambiente de trabalho colaborativo. Nesse contexto, pode-se concluir que a não adoção desse sistema implicaria uma diferente forma de atuação de BETA para atender seu mercado consumidor.

\section{Conclusão}

As conclusões da pesquisa passam pela análise de como ALFA e BETA fizeram a adoção da tecnologia de groupware e como ela interagiu com as propriedades institucionais (estratégia e estrutura) das organizações e com os agentes humanos.

Em ALFA, não houve mudanças na estrutura organizacional exclusivamente em função do uso da tecnologia. Essas mudanças já vinham sendo empreendidas há anos e, como detectado na pesquisa, a adoção da tecnologia foi motivada pela necessidade de atender novas formas de trabalho, provocadas pelas mudanças ocorridas.

A tecnologia veio como uma ferramenta para suportar a estrutura organizacional predominante; a padronização nos processos de trabalho (mecanismo de coordenação), bem como especialização de tarefas com divisão básica do trabalho e agrupamento das unidades com supervisão di reta em cada uma delas (características dos Parâmetros Essenciais) puderam ser reforçados por aplicações estruturadas de apoio à operação e tomada de decisão providas pela tecnologia de groupware. Por outro lado, alguns pequenos ajustes foram efetuados na estrutura organizacional para prover a adequação dos recursos de groupware disponibilizados, de maneira que a tecnologia pudesse ser eficaz em sua utilização.

A análise da interação entre TI e agentes humanos aponta a aceitação - facilitada pela tendência a mudanças constantes que predomina na organização - motivação e até entusiasmo geral na adoção e uso do ambiente de groupware (correio, agenda - individual e de grupo - e aplicações desenvolvidas): é a TI influenciando as pessoas ao disponibilizar recursos que melhorem sua forma de trabalho. Em sentido contrário, a percepção de vantagens advindas do uso desse ambiente faz com que, a cada dia, surjam novas demandas, quando áreas diversas de ALFA solicitam à equipe de informática que desenvolvam aplicações para automatizar processos, até então administrados manualmente; é a ação dos agentes humanos promovendo a intensificação do uso da TI. Sobre as demandas para desenvolver novas aplicações, uma característica comum, identificada durante as entrevistas, foi o fato de que antes de as aplicações serem desenvolvidas houve uma evolução no entendimento dos processos manuais de trabalho, na expectativa de informatizar rotinas reavaliadas e, em alguns casos, incrementadas ou reestruturadas, de maneira que a aplicação adotada apoiasse a administração de um processo mais eficaz e redesenhado para otimizar as atividades empreendidas pela área.

BETA, mesmo sendo pequena e simples, congregando um número reduzido de colaboradores, serviu a esta pesquisa como referência para mostrar como uma tecnologia pode ser adotada para servir como ferramenta para o desenvolvimento das atividades de negócios, visto que a organização já nasceu estruturada com base no uso da tecnologia de groupware. Falar em mudança na estrutura organizacional não faz sentido, mas sim, em nascimento de uma estrutura organizacional fora dos padrões convencionais de divisão do trabalho, adotados na maioria das organizações. Esta estrutura é voltada para o trabalho em equipe que responde a demanda e oferta de informações tecnológicas. Dessa maneira, estrutura organizacional e estrutura dos processos de TI têm estreita ligação para suportar as 
atividades organizacionais.

Nesse contexto, as pessoas, de maneira geral, que atuam em BETA se adaptaram ao uso de recursos de TI desde o início de suas atividades, tendo suas ações orientadas pelos recursos da tecnologia postos à sua disposição. E, embora haja alguma resistência, novas demandas têm surgido no sentido de incrementar o uso do ambiente de groupware, desenvolvendo outras aplicações que ajudem a melhorar a eficácia das operações da instituição.

As organizações analisadas, usando de maneira intensa a tecnologia de groupware, mostram a aplicabilidade do Modelo de Estruturação Tecnológica, proposto por Orlikowski (1992), baseado nos componentes - Tecnologia, Propriedades Institucionais e Agentes Humanos.

No caso de ALFA, a avaliação qualitativa dos resultados da implementação do ambiente de groupware mostrou uma satisfação generalizada com a adoção do sistema, reforçando a hipótese de que se a TI e as propriedades institucionais (estrutura) estão em consonância é mais fácil atingir bons resultados. Sobre a relação entre a TI e a estrutura, a discussão é simples: ALFA é considerada, pelos seus atores, como uma organização em constante mudança, usando a tecnologia para suportar as operações e processos de trabalho redesenhados.

Para BETA, as conclusões são mais simples, pois a Tecnologia foi identificada e adotada durante a concepção da organização, de maneira que interagisse com a estrutura (Propriedades Institucionais) da organização. Pode-se inferir, com base na visão da maioria das pessoas entrevistadas, que esses elementos, de certa forma, se fundiram, tornando-se a própria organização. Por outro lado, as pessoas (Agentes Humanos) têm uma interação ativa com a tecnologia; quando a aprovam, usam-na ou até mesmo rejeitam-na; orientando a disseminação do recurso tecnológico entre as coordenações e restringindo seu uso em uma delas.

Os resultados apontados em ambos os casos indicam uma satisfação quase geral com o uso do software, como retratado nos tópicos anteriores. Os focos de resultados ruins (em ALFA) e resistência (em BETA) não foram suficientes para condenar a adoção. Mais que isso, eles podem servir como guia para avaliar a processo de implementação à luz do modelo considerado, prestando-se a confirmar a hipótese sobre a importância de se tratar Tecnologia associada a Propriedades Institucionais e a Agentes Humanos. Isto reforça a importância de se considerar que a implantação de um recurso de TI não se processa em um vácuo organizacional, devendo ser tratada como um elemento que se alinhe à sua estrutura. Numa organização, a configuração estrutural e a forma de trabalho podem ajudar ou prejudicar a adoção de um recurso de TI. Se a organização não tiver processos maturados ou se prestar a reavaliá-los, a implementação de uma tecnologia, por mais inovadora ou sofisticada que seja, pode não trazer benefício nenhum.

Não se deve esquecer outro fator relevante, a ação dos agentes humanos. Em qualquer organização, existem diversos grupos de interesse - acionistas, gerentes, empregados de diversos níveis, fornecedores, parceiros de negócio e clientes. Congregar os desejos desses grupos pode ser complicado, havendo casos, como o citado em BETA, em que simplesmente se ignora a adoção da tecnologia pelo fato de ela não estar em consonância com os objetivos pretendidos pelo grupo. E ainda, a participação dos diversos interessados pela tecnologia adotada deve ocorrer desde as fases iniciais do processo de implementação, pois só assim haverá comprometimento e condições para que a tecnologia adotada seja de fato utilizada adequadamente, possibilitando a todos evoluírem na forma de pensar em seu trabalho e em como atingir os objetivos de negócio da organização. 


\section{Artigo recebido em 31.10.2002. Aprovado em 08.09.2003}

\section{REFERÊNCIAS BIBLIOGRÁFICAS}

AL-OMAIM, N. (1997). What is groupware? Disponível na Internet.

http://www.usfca.edu/fac-staff/morriss/478/projects_972/webdoc4.htm.

BRYNJOLfSSON, E. \& MENDELSON, H. (1993) Information systems and the organization of modern enterprise. Journal of Organizational Computing, December.

BRYNJOLFSSON, E. \& HITT, L. (1993.B) Is Information systems spending productivity new evidence and new results. International Conference. Orlando. dez.

CANDOTTI, C. T. \& HOPPEN, N. Reunião virtual e o uso de groupware - uma nova possibilidade de realizar trabalho em grupo. ENANPAD, 1999.

Carvalho, R.B. \& Ferreira, M. A. T. (2000) Análise de software de gestão do conhecimento. XXI Simpósio de gestão da inovação tecnológica. São Paulo:nov.

CASTElls, M. (1999), A Sociedade em rede - A era da informação: economia, sociedade e cultura. São Paulo: Paz e Terra. V.1 2ed.

CLEGG, S. (1994). Weber and foucault: social theory for the study of organizations. Organization, v.1, no. 1, p. 149-178.

CHILD, J. \& LOVERIDGE, R. (1990). Information technology in european services. Oxford: Basil Blackwell (Capítulo 2: Perspectives on Technology and Organizations).

CiBORRA, C. \& SCHNEIDER, L. (1992) Transforming the routines and contexts of management, work and tecnology. Em Adler, P. (org.) Technological and the future of the work. Oxford: Oxford University Press.

DiAS, D. S. (2000). Motivação e resistência ao uso da tecnologia da informação: um estudo entre gerentes. RAC - Revista de Administração Contemporânea, v. 4, no.. 2. p 51-66. mai/ago.

DORNELAS, J. S. \& HOPPEN, N. Inovações ligadas ao processo de gestão participativa e ao uso de sistemas de apoio à decisão em grupo, na direção de novas formas de estruturas organizacionais. ENANPAD, 1999

GROUPWARE CONCEITOS \& TECNOLOGIA. (1999). Boletim da Lotus/IBM Brasil. Mai.

Groupware AND COMPUTER SUPPORTED COOPERATIVE WORK. (2000). Disponível em. http://www.scit.wlv.ac.uk/ cm1906/din. groupware/sld004.htm. Acesso em: 2, Set. 2000.

HALL, R. N. (1984), Organizações: estruturas e processos. 3. ed. Rio de Janeiro: Prentice-Hall do Brasil.

HAMMER, M. \& CHAMPY, J. (1994). Reengenharia: revolucionando a empresa. Rio de Janeiro: Campus. 29ed. 
HAMMER, M. (1998). A Empresa voltada para processos. Revista HSM Management, n. ${ }^{\circ}$ 09, ano II, jul-ago.

HENDERSON, J. C. \& VENKATRAMAN (1994). Strategic alignment: a model for organizational transformation via information technology. Em: Allen, T. \& Scott Morton, M. (orgs), Information Technology and the Corporation of the 1990s. New York: Oxford University Press.

HERNANDEZ, J. M. C. \& CALDAS, M. P. (2001). Resistência à mudança: uma revisão crítica. São Paulo. RAE - Revista de Administração de Empresas. V. 41 - no . 2 - p.31-45. Abr/Jun.

LIKERT, R. (1971). Novos padrões de administração. $1^{a}$ Ed. SÃO PAULO: Livraria Pioneira Editora. $306 \mathrm{p}$.

MarCOVITCH. J. (1996) org. Tecnologia da informação e estratégia empresarial. $1^{\text {a }}$ ed. São Paulo: Futura. 130p.

MinTZBERG, H. (1995). Criando organizações eficazes - Estruturas em cinco configurações. São Paulo: Atlas..

MinTZBERG, H. (1981). Organization design: fashion or fit?. Harvard Business Review, jan/fev.

MiNTZBERG, H. (1980). Structure in 5's a synthesis of the research on organization design. Management Science, v. 26, n. 3 , Mar.

MotTA, P. R. (1998) Transformação organizacional: a teoria e a pratica de inovar. Rio de Janeiro: Qualitymark.

ORLIKOWSKI, W. J.(1992). The duality of technology: rethinking the concept of technology in organizations. Organization Science, n. ${ }^{\circ} .3$ p. 398-426.

ROBERTS, K \& GRABOWSKY, M. (1996). Organizations, technology and structing. Em Clegg, S. Hardy, C \& Nord, W. (orgs.), Handbook of organization studies. Londres: Sege Publications.

SANTOS, J. F. \& VIEIRA, M. M. F. (1998). Mudança tecnológica e mecanismos de coordenação: A introdução da informática em uma empresa de construção civil. Anais do $22^{\circ}$ ENANPAD.

SElltiZ, C. ET AL (1965). Métodos de pesquisa das relações sociais. $1^{\text {a }}$ ed. São Paulo: Herder, 715p.

SteIL, A. V., M.A. \& BARCIA, R. M. (1999). Aspectos estruturais das organizações virtuais. Anais do $23^{\circ}$ ENANPAD, Foz do Iguaçu

StRASSMANN, P. (1986). Os frutos da Informática. Rio de Janeiro: José Olympio.

STRASSMANN, P. (1997). The squandered computer: evaluating the businness alignment of information technologies. New Canaan: The Information Economics Press.

TAPSCOTT, D. \& CASTON A (1995). Mudança de paradigma: a nova promessa da tecnologia de informação. São Paulo: Makron Books - McGraw Hill.

VASCONCEllos, E. \& HeMSLey, J. R. (1997). Estrutura das organizações. São Paulo: Pioneira 


\section{GESTÃO DA INFORMAÇÃO - ADOTANDO A TECNOLOGIA DE INFORMAÇÃO: ANÁLISE DA IMPLEMENTAÇÃO DE SISTEMAS DE "GROUPWARE" \\ Edna Campos - Francisco Lima C. Teixeira}

Venkatraman, N. (1994). IT enabled business transformation: From Automation to Business Scope Redefinition Sloan Management Review. Winter.

ZANELA, A. C.\& MACADAR, M. A. \& SOARES, R. O. (1999). Mudança organizacional provocada pela utilização de sistemas integrados de gestão empresarial: Uma proposta de estudo. Anais do $23^{\circ}$ ENANPAD - Área Temática: Administração De Informação, Foz Do Iguaçu Set.

\footnotetext{
${ }^{\mathrm{i}}$ Conceito considerado: Qualquer transformação de natureza estrutural, estratégica, cultural, tecnológica, humana ou de qualquer outro componente, capaz de gerar impacto em partes ou no conjunto da organização. (Wood, Curado \& Campos, 1995, p.190).

ii A comunicação não acontece em tempo real, a mensagem é enviada e o receptor não precisa responder imediatamente, ele responderá quando puder.
}

\section{Edna Campos}

Professora de Administração de Sistemas de Informação e Consultora de empresas em Sistemas de Informação. Mestre em Administração pelo NPGA/UFBA. Pós-graduada La tu Sensu em Gestão Empresarial pelo NPGA/UFBA e em Análise de Sistemas pelo IBPI. Graduada em Matemática pela UFU.

E-mail: edna@br.ibm.com

Ende reço: Rua do Timbó, no 519 - 801B - Caminho das Árvores, Salvador - BA, 41820-660.

Interesses de Pesquisa: Tecnologia da Informação, Inovação e Mudança Organizacional.

\section{Francisco Lima C. Teixeira}

Professor Titular e Coordenador do NPGA / UFBA. Pesquisador do NACIT - Núcleo de Política e Administração em Ciências e Tecnologia - NPGA / UFBA. PHD em Sussex - Inglaterra.

E-mail: teixeira@ufba.br

Endereço: Av. Reitor Miguel Calmon , s/n - Vale do Canela, Salvador - BA, 40110-100.

Interesses de Pesquisa: Gestão e Política de Inovação, Inovação e Mudança Organizacional. 